\title{
The Science of Selecting Antimicrobials for Community-Acquired Pneumonia (CAP)
}

\author{
Thomas M. File, Jr., MD, MSc, FIDSA
}

\begin{abstract}
BACKGROUND: Among infectious diseases, community-acquired pneumonia (CAP) is the leading cause of death in the United States and is associated with a substantial economic burden to the health care system. Initiating appropriate empiric therapy can be challenging given elevated resistance rates among Streptococcus pneumoniae strains.

OBJECTIVE: To present current recommendations for management of CAP with respect to (a) choosing the appropriate site of care, and (b) antimicrobial selection based on bacterial etiology and the prevalence of resistance.

SUMMARY: Mortality prediction tools, such as the PORT (Pneumonia Outcomes Research Team) Severity Index, CURB-65 (Confusion, Urea concentration, Respiratory rate, Blood pressure, and age $>65$ ), or CRB-65 (Confusion, Respiratory rate, Blood pressure, and age $>65$ ), can be invaluable in determining which CAP patients require hospitalization. These tools can help reduce overall costs for CAP by limiting hospitalizations of low-risk patients. $S$. pneumoniae remains the most common causative pathogen for CAP across all disease severities, and elevated rates of resistance to penicillin and macrolides can hinder selection of appropriate antimicrobial therapy. Antimicrobial resistance can impact clinical outcomes, including increasing the risk of treatment failure and breakthrough bacteremia. Current management guidelines recommend monotherapy with a respiratory fluoroquinolone or combination therapy with a $\beta$-lactam and a macrolide (for patients admitted to the general medical ward) or with a $\beta$-lactam and either a respiratory fluoroquinolone or a macrolide (for patients admitted to the intensive care unit [ICU] and who do not have risk factors for methicillin-resistant $S$. aureus or Pseudomonas). Optimized dosing regimens aim to ensure that pharmacokinetic and pharmacodynamic targets are met to achieve successful clinical outcomes and minimize resistance development.
\end{abstract}

CONCLUSION: Effective management of patients with CAP requires selection of the proper site of care and appropriate empiric antimicrobial. Given the elevated rates of resistance among $S$. pneumoniae, local resistance patterns must be considered when choosing empiric therapy.

J Manag Care Pharm. 2009;15(2)(Suppl):S5-S11

Copyright@ 2009, Academy of Managed Care Pharmacy. All rights reserved.

Author

THOMAS M. FILE, Jr., MD, MSc, is Professor of Internal Medicine, Master Teacher, and Head, Infectious Disease Section, Northeastern Ohio Universities Colleges of Medicine and Pharmacy, Rootstown, Ohio, and Chief, Infectious Disease Service, Summa Health System, Akron, Ohio.

CORRESPONDENCE: Thomas M. File, Jr., MD, MSc, 75 Arch Street, Suite 105, Akron, OH 44304. Tel.: 330.375.3894; Fax: 330.375.6680; E-mail: filet@summa-health.org ommunity-acquired pneumonia (CAP) along with influenza is the leading cause of death among infectious diseases in the United States (and eighth leading cause of death overall). ${ }^{1}$ Five to 6 million cases occur each year, with persons 65 years or older accounting for about one million cases. ${ }^{2}$ An estimated $20 \%$ of the patients with CAP require admission to the hospital. ${ }^{3}$ The mortality rate of patients who require admission to the hospital averages 12\% overall but increases to 30\%-40\% for those with severe CAP who require admission to the ICU. ${ }^{2}$ This compares to a mortality rate of less than $1 \%$ among patients with CAP treated on an outpatient basis. ${ }^{4}$ In addition to the clinical consequence of CAP, the economic cost is extraordinary, with one study estimating the cost for each inpatient episode of CAP to exceed $\$ 10,000$. $^{3}$

It is noteworthy that these clinical and economic consequences of CAP occur against the backdrop of effective antimicrobial agents available for the treatment of respiratory tract infections. Many factors must be considered in order to select an appropriate antimicrobial regimen for effectively treating patients with CAP. The first and foremost consideration should be whether an antimicrobial agent is warranted. Viral infections can play a role in a significant portion of patients hospitalized for CAP, with estimates ranging from $1 \%$ to $23 \% .^{5}$ Several observational studies have shown that over $50 \%$ of the patients with viral respiratory tract infections are inappropriately prescribed antimicrobial agents. ${ }^{6,7}$ Antimicrobial overuse and inappropriate antimicrobial selection have been associated with increased drug resistance among several respiratory pathogens. In addition, unnecessary use increases cost and potential adverse events.

Increasing resistance has made judicious use of antimicrobials an imperative, ${ }^{8}$ and differentiating viral bronchitis from pneumonia is key in limiting unnecessary antimicrobial use. Unfortunately, there is lack of rapidly available, cost-effective diagnostic tests that reliably differentiate self-limiting viral infections from bacterial infections. However, practice guidelines can offer pragmatic criteria for better antimicrobial usage. ${ }^{9}$

Once a patient is diagnosed with CAP, optimal management should be based on the site of care, the severity of CAP, the resistance profiles of bacteria, and the pharmacokinetic-pharmacodynamic targets that ensure bacterial eradication.

\section{Site of Care}

Site of care in patients with CAP impacts the overall cost of treatment, the intensity of diagnostic testing, and options for empiric antimicrobial selection. The decision to admit a patient with CAP is based on (a) mortality prediction rules, such as the PORT (Pneumonia Outcomes Research Team) Severity Index (PSI) score or CURB-65 (Confusion, Urea concentration, Respiratory rate, Blood pressure, and age $>65$ ), (b) social circumstances of the patient, and (c) co-existing conditions.

Hospitalization. Hospitalization should be considered when (a) patients have pre-existing conditions that may compromise the safety of home care, (b) patients have hypoxemia, (c) patients are unable to take oral medications, or (d) psychosocial factors can 


\begin{tabular}{c|c|c}
\hline TABLE 1) & $\begin{array}{c}\text { Common Etiologies of Community- } \\
\text { Acquired Pneumonia }\end{array}$ \\
\hline & $\begin{array}{c}\text { Hospitalized (non-ICU) } \\
\text { Patients }^{\mathrm{b}}\end{array}$ & Severe (ICU) Patients \\
\hline Ambulatory Patients & S. pneumoniae & S. pneumoniae \\
\hline S. pneumoniae & M. pneumoniae & S. aureus \\
M. pneumoniae & C. pneumoniae & Legionella spp. \\
H. influenzae & H. influenzae & Gram-negative bacilli \\
C. pneumoniae & Legionella spp. & H. influenzae \\
Respiratory viruses & \\
& Aspiration respiratory & \\
& viruses & \\
\hline
\end{tabular}

aSource: Collective data from recent studies; modified from: File TM. Lancet. 2003;362:1991-2001. ${ }^{5}$ Reprinted from The Lancet Vol. 362, File TM, Communityacquired pneumonia, 1991-2001 (2003) with permission from Elsevier.

${ }^{b}$ Excluding Pneumocystis spp.

'Influenza $A$ and $B$, adenovirus, respiratory syncytial virus, parainfluenza. ICU = intensive care unit.

potentially impact effective treatment (such as an unstable home environment or psychiatric disorders that may hinder adherence to therapy). ${ }^{9}$ Mortality prediction tools can also help guide clinicians in making the decision to hospitalize the patient.

The PORT Prediction Rule, developed over 10 years ago, offers important insights into the risk of mortality (Figure 1). ${ }^{10}$ This technique uses a combination of demographic variables, co-morbidities, physical observations, and laboratory and radiographic variables to assign patients to 1 of 5 classes. Those belonging to PSI Class 1 or 2 have a low risk of mortality $(<1 \%)$ and can be treated as outpatients. Those in PSI Class 3 have a slightly higher risk of mortality $(<5 \%)$ and may require a brief observational stay in a hospital. Those in PSI Class 4 or 5 have the highest mortality risk (8\%-30\%) and will require hospitalization-those in PSI Class 5 should be admitted to an ICU. Though the PORT Prediction Rule is effective in determining mortality risk, it is not the most practical approach in the clinical setting as it is based on laboratory findings that can be costly and time consuming.

The CURB-65 Rule uses 5 aspects in making a clinical determination-confusion, urea concentration, respiratory rate, blood pressure, and age (Figure 2). ${ }^{11}$ Those meeting 2 or more of the criteria should be considered for hospitalization. However, this method requires a blood sample and laboratory analysis for urea concentration. In response to this, the CRB-65 was designed. It omitted the blood urea measurement and was practical for officebased settings. ${ }^{12}$ In CRB-65, a score of 0 equates to home treatment, a score of 1 to hospital-supervised treatment, and a score of 2 or more to hospitalization.

A study comparing the mortality rates using PSI, CURB-65, and CRB-65 showed a strong correlation among the 3 methods. ${ }^{12}$

Admission to the ICU. Recommendation regarding admission to the ICU is provided by the Infectious Diseases Society of America (IDSA)/American Thoracic Society (ATS) guidelines about management of CAP. According to the IDSA/ATS guidelines, direct admission to the ICU is essential for patients with septic shock requiring vasopressor or for patients with acute respiratory failure requiring intubation and mechanical ventila- tion. ${ }^{9}$ ICU admission should also be considered for patients who have 3 or more of the following: confusion/disorientation, uremia (blood urea nitrogen $\geq 20 \mathrm{mg}$ per $\mathrm{dL}$ ), respiratory rate $\geq 30$ breaths/minute, hypotension requiring aggressive fluid resuscitation, $\mathrm{PaO} / \mathrm{FiO}_{2}$ ratio $\leq 250$, multilobar infiltrates, leukopenia (WBC $<4000$ cells $/ \mathrm{mm}^{3}$ ), thrombocytopenia (platelet count $<100,000$ cells $/ \mathrm{mm}^{3}$ ), or hypothermia (core temperature $<36^{\circ} \mathrm{C}$ ).

\section{Bacterial Etiology of CAP}

Bacterial etiology varies slightly according to the severity of CAP (Table 1). ${ }^{5}$ Streptococcus pneumoniae remains the most common cause of CAP across all severities. Mycoplasma pneumoniae, Haemophilus influenzae, and Chlamydophila pneumoniae are associated with mild-to-moderate CAP and Staphylococcus aureus, Legionella species, and gram-negative pathogens, including Klebsiella pneumoniae and Pseudomonas aeruginosa, are more likely to be associated with severe CAP. Recently, communityassociated methicillin-resistant Staphylococcus aureus (MRSA) has also been observed as a cause of severe CAP. The probable causative pathogens influence the diagnostic measures and empiric treatment strategies, including the use of combination therapy and gram-negative coverage.

\section{Bacterial Resistance}

Among community-acquired respiratory tract pathogens, $S$. pneumoniae remains the primary focus given its predominance as the causative pathogen, including severe infections ${ }^{5}$ and antimicrobial resistance to several commonly used agents. ${ }^{13-17}$ Multiple antimicrobial surveillance programs have been instituted in the United States to track the susceptibility trends of S. pneumoniae.

Penicillin Resistance. Increasing penicillin resistance of $S$. pneumoniae has been reported since the early 1990s with a peak at about $40 \%$ (high-level plus intermediate-level resistance) in 2000 (Figure 3). ${ }^{13-15}$ Since 2000, resistance to penicillin has remained stable, though at an elevated level. A surveillance study in 2005-2006 involving 1,543 isolates showed high-level penicillin resistance at $16 \%$ and intermediate resistance at $21 \%{ }^{16}$

The clinical relevance of penicillin-resistant S. pneumoniae (PRSP) is controversial. Available data suggest that clinically relevant levels of penicillin resistance most likely occur at a minimal inhibitory concentration (MIC) of $\geq 4 \mu \mathrm{g}$ per $\mathrm{mL}$. This is reflected in the new 2008 Clinical and Laboratory Standards Institute breakpoints (formerly NCCLS) for parenteral penicillin $\mathrm{G}$ - susceptible $(\leq 2 \mu \mathrm{g}$ per $\mathrm{mL})$, intermediate $(4 \mu \mathrm{g}$ per $\mathrm{mL})$, and resistant $(\geq 8 \mu \mathrm{g}$ per $\mathrm{mL}$ )—for nonmeningeal infections such as CAP. ${ }^{18}$ These changes will reduce the reported rate of resistance and hopefully assist clinicians in predicting which patients are at a greater risk for clinical failure due to a resistant strain.

Macrolide Resistance. Macrolide resistance of S. pneumoniae has increased steadily since the 1990s, approaching 30\% by the early 2000s (Figure 3). ${ }^{15,17}$ The level of macrolide resistance has remained steady over the past few years, though a recent surveillance study from 2005-2006 estimated 34\% macrolide resistance in the United States. ${ }^{16}$

Fluoroquinolone Resistance. Fluoroquinolone resistance of $S$. pneumoniae is rare-surveillance studies demonstrate resistance rates of $1 \%$ or less. ${ }^{13,17} \mathrm{~A}$ recent study showed nonsusceptibility to levofloxacin to be less than $1 \%$ in 2005-2006 (0.6\% resistance 
FIGURE 1 Pneumonia PORT Prediction Rule for Mortality Risk Assessment ${ }^{a}$

Step 1

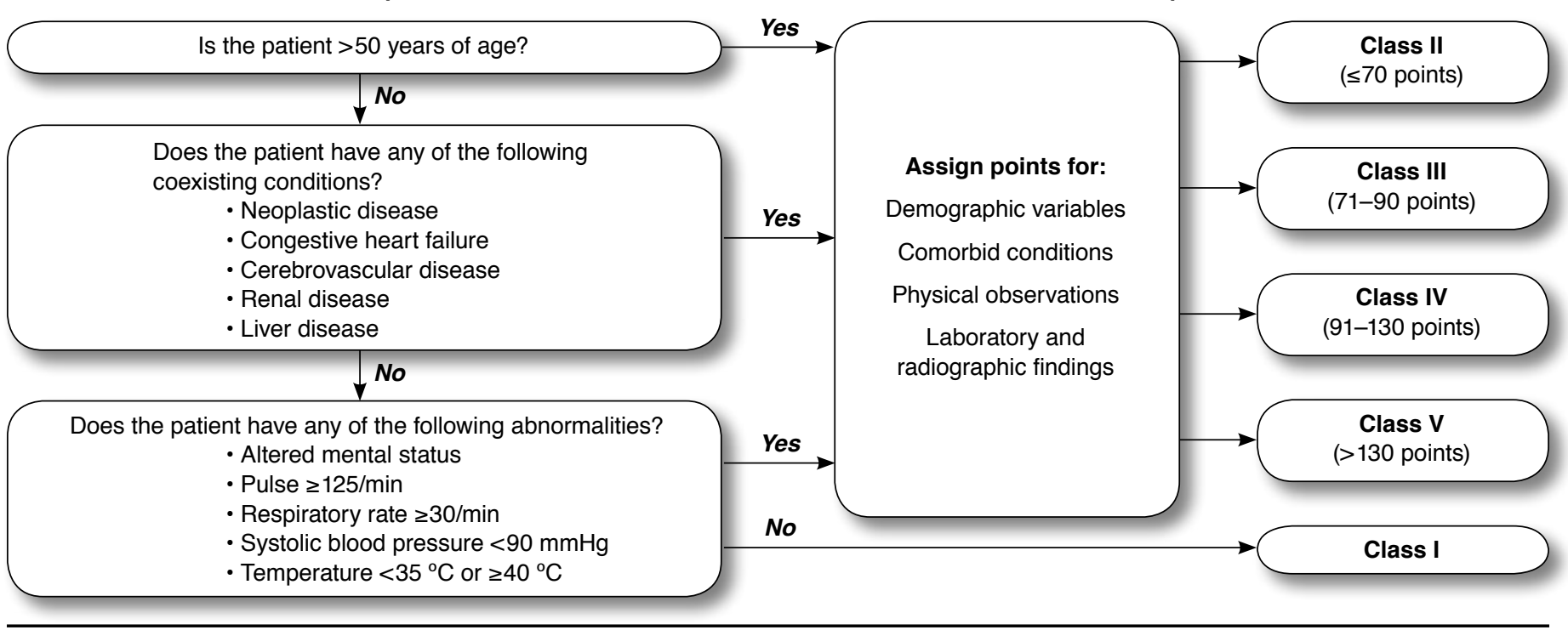

aAdapted from: Fine MJ, Auble TE, Yealy DM, et al. N Engl J Med. 1997;336(4):243-50.10

${ }^{b}$ Point scoring system for Step 2 of the Prediction Rule for assignment to Risk Classes II, III, IV, and V includes the following:

- Demographic factor (Age): men (Age [year]), women (Age [year]-10)

- Nursing home resident: +10

- Coexisting illness: neoplastic disease (+30), liver disease $(+20)$, congestive heart failure $(+10)$, cerebrovascular disease $(+10)$, renal disease $(+10)$

- Physical examination findings: altered mental status ( +20$)$, respiratory rate $\geq 30 / \mathrm{min}(+20)$, systolic blood pressure $<90 \mathrm{mmHg}(+20)$, temperature $<35^{\circ} \mathrm{C}$ or $\geq 40^{\circ} \mathrm{C}$ $(+15)$, pulse $\geq 125 / \min (+10)$

- Laboratory and radiographic findings: arterial $\mathrm{pH}<7.35$ (+30), blood urea nitrogen $\geq 30 \mathrm{mg} / \mathrm{dL}(+20)$, sodium $<130 \mathrm{mmol} / \mathrm{L}(+20)$, glucose $\geq 250 \mathrm{mg} / \mathrm{dL}(+10)$, hematocrit $<30 \%(+10)$, partial pressure of arterial oxygen $<60 \mathrm{mmHg}(+10)$, pleural effusion $(+10)$

\section{FIGURE 2 Applying the CURB-65 Rulea}

CURB-65 Score

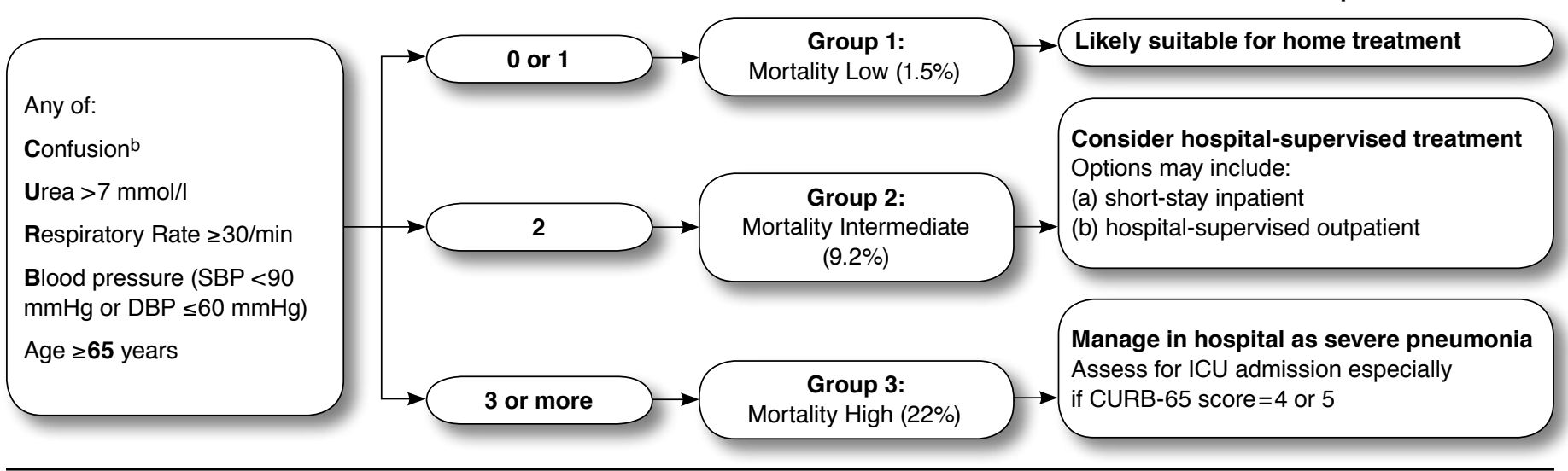

aReproduced from Defining community-acquired pneumonia severity on presentation to hospital: an international derivation and validation study. Lim WS, van der Eerden MM, Laing R, et al. Thorax. 2003;58(5):377-82.11 ( 2009 BMJ Publishing Group Ltd and the British Thoracic Society; with permission from BMJ Publishing Group Ltd.

${ }^{b}$ Defined as a Mental Test Score of 8 or less, or new disorientation in person, place, or time.

Note: 1 point is assigned to each of the components if present. 


\section{FIGURE 3 Penicillin-Resistant and Macrolide-Resistant S. pneumoniae In Vitro ${ }^{a}$}

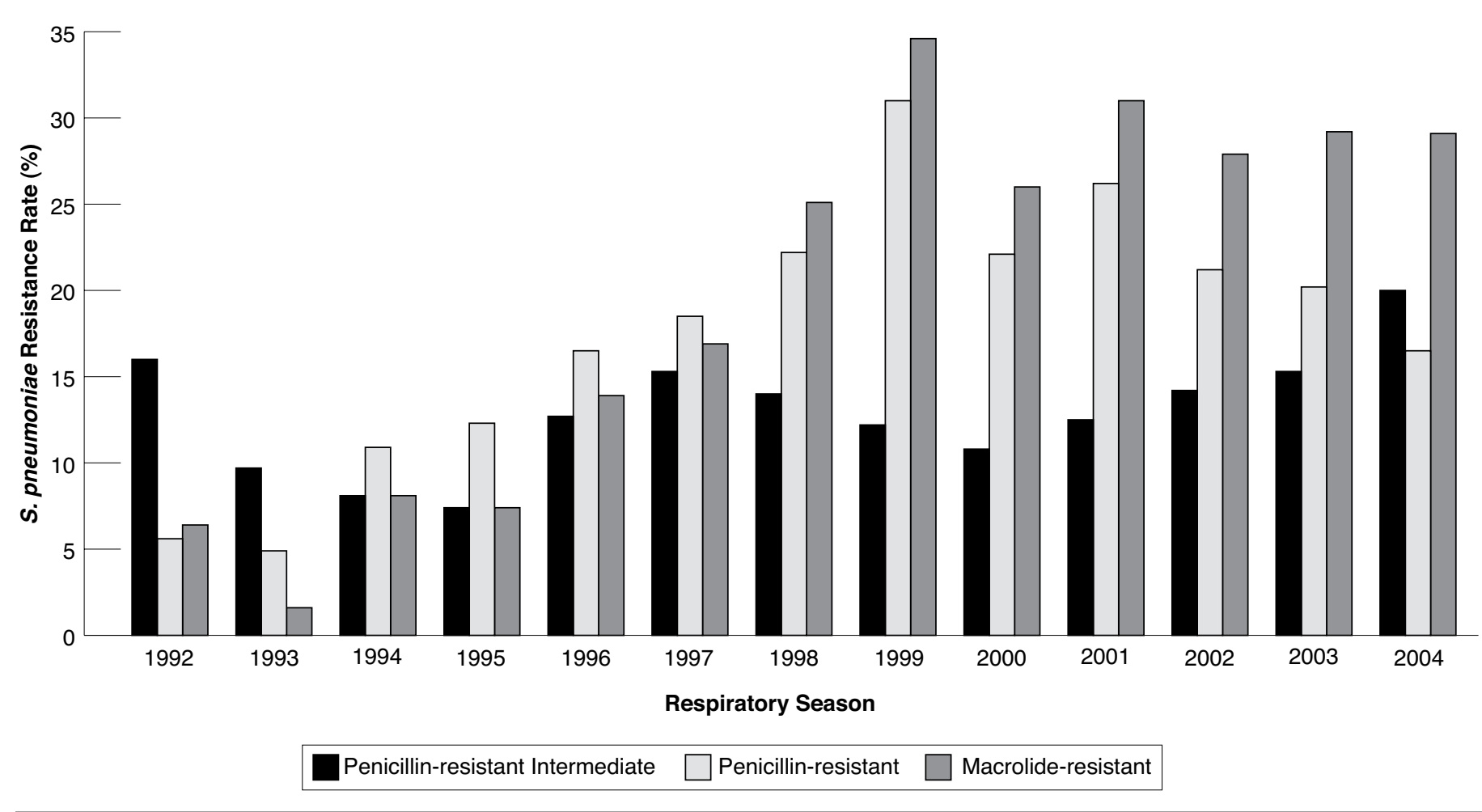

aSources: Karchmer AW; ${ }^{13}$ Doern GV, Brown SD;14 The Alexander Network:15 Karlowsky JA, et al. ${ }^{17}$

Penicillin-resistant intermediate $=$ MIC 0.12-1 $\mu \mathrm{g}$ per $\mathrm{mL}$; penicillin-resistant $=$ MIC $\geq 2 \mu \mathrm{g}$ per $\mathrm{mL}$; macrolide-resistant $=$ erythromycin-resistant $=$ MIC $\geq 1 \mu \mathrm{g}$ per $m \mathrm{~mL}$.

and $0.2 \%$ intermediate resistance). ${ }^{16}$ Despite the continued low level of resistance to fluoroquinolones, it is important to use them judiciously to preserve their utility.

Antimicrobial Resistance by Geographic Region. Antimicrobial resistance can vary considerably by geographic region. The Prospective Resistant Organism Tracking for the Ketolide Telithromycin (PROTEKT) study showed that the highest levels of penicillin and macrolide resistance were in the southeastern and south-central regions of the United States (high-level penicillin resistance of 33\%-36\% and macrolide resistance of $39 \%-40 \%$ ), and the lowest were in the northwestern region (high-level penicillin resistance of $17 \%$ and macrolide resistance of 23\%). ${ }^{13}$ Therefore, the knowledge of local resistance profiles is critical to guide appropriate selection of an antimicrobial agent.

Clinical Impact of Resistance. The clinical relevance of $\beta$-lactam resistant pneumococcal pneumonia appears most relevant to specific MICs for specific antimicrobials. ${ }^{19}$ Many studies are hampered by small sample sizes, biases inherent in observational design, and the relative infrequency of clinical isolates showing high-level resistance. One study evaluated time to symptom resolution in 17 pneumococcal pneumonia patients (5 of whom were infected with a penicillin-resistant strain) who were treated with procaine penicillin. ${ }^{20}$ Those with a resistant infection experienced a longer time before resolution of fever (3.6 vs. 1.9 days), cough and sputum production (6.0 vs. 2.7 days), and pleuritic pain (3.6 vs. 2.1 days), compared to patients with susceptible infections. In a study from the Centers for Disease Control and Prevention of bacteremic pneumococcal pneumonia, investigators found that after hospital day 4 , the risk of death was 7 times greater in patients infected with high-level PRSP (MIC $\geq 4.0 \mu \mathrm{g}$ per $\mathrm{mL} ; 19 / 1,151$ patients) than in patients infected with intermediate isolates (MIC $=0.012-1.0 \mu \mathrm{g}$ per $\mathrm{mL} ; 81 / 1,151$ patients). ${ }^{21}$ However, treatment and severity of disease were not recorded.

Subsequently, a follow-up, case-control study of patients with bacteremic pneumococcal pneumonia was conducted, which addressed the limitations of the trial by Feikin et al. (2000) and controlled for risk factors, severity, and treatment. ${ }^{22}$ The findings from this multivariate analysis showed no contribution of antimicrobial resistance to mortality or requirement for ICU admission, but determined that more important predictors of outcome included severity of illness and whether there was a "do not resuscitate" order on the patient's chart. Findings from a more recent large observational study suggest that current levels of $\beta$-lactam resistance generally do not cause treatment failures when appropriate agents (i.e., amoxicillin, ceftriaxone, cefotaxime) and doses are used. ${ }^{23}$ However, discordant therapy with cefuroxime in patients with pneumococcal bacteremia has been associated with an excessively high failure rate com- 


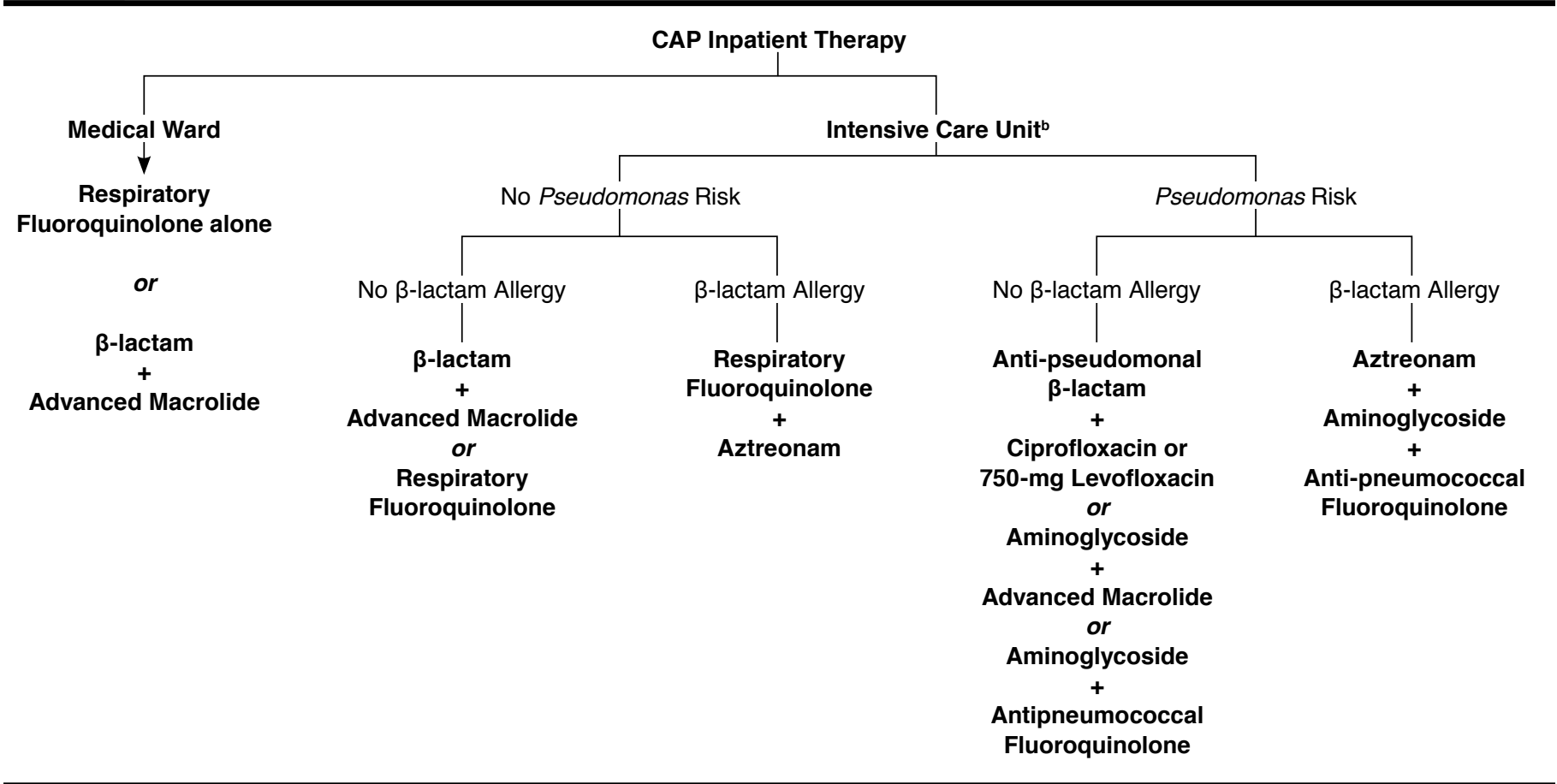

a Source: Mandell LA, et al. ${ }^{9}$

bIf community-associated methicillin-resistant Staphlococcus aureus (MRSA) is a concern, add vancomycin or linezolid.

$C A P=$ community-acquired pneumonia; IDSA/ATS = Infectious Diseases Society of America/American Thoracic Society.

pared with other discordant therapies

The clinical impact of macrolide resistance is well established. Antimicrobial resistance is associated with an increased risk of breakthrough bacteremia in patients with CAP. In a prospective, population-based study by Daneman et al. (2006), pneumococcal bacteremia cases were identified among patients who received macrolide treatment. ${ }^{24}$ These treatment failures were then documented based on the isolate MIC. Clinical failure was observed in $1.5 \%$ (21 of 1,397) of episodes where isolates were susceptible to erythromycin (MIC $\leq 0.5 \mu \mathrm{g}$ per $\mathrm{mL}$ ) but it was $16 \%$ (37 of 230) for infections caused by resistant strains (MIC $\geq 1 \mu \mathrm{g}$ per $\mathrm{mL}$ ). Other studies are associated with similar results suggesting that macrolide resistance can be an important cause of clinical failure. ${ }^{25-27}$

Several case reports of treatment failures due to fluoroquinolone-resistant pneumococcal infections in adults with CAP have also been reported. ${ }^{28,29}$ Many of the patients described in these reports had been previously treated with fluoroquinolones.

Risk Factors for an Antimicrobial-Resistant Infection. Given the clinical significance of antimicrobial resistance, it is important to identify factors that may increase the risk of an infection by a resistant organism. These include age (either $>65$ years or $<5$ years), noninvasive disease, alcoholism, exposure to a child who attends day care, or multiple co-morbidities. ${ }^{30-32}$ Prior exposure to an antimicrobial is also a major cause of antimicrobial resistance. ${ }^{30,31}$ One study showed that exposure to a $\beta$-lactam in the previous 3 months significantly increased the risk of peni- cillin resistance in a subsequent infection. ${ }^{30}$ Prior macrolide use has also been shown to increase the risk of a macrolide-resistant infection, though the risk is significantly greater with prior azithromycin use than with prior clarithromycin or erythromycin use. ${ }^{31}$ Prior fluoroquinolone use also increases the risk of a fluoroquinolone-resistant infection. ${ }^{31}$

The strong association of prior antimicrobial use with subsequent antimicrobial resistance should be an important consideration when selecting empiric therapy for patients with CAP. Antimicrobial usage during the previous 3 months should be noted for each patient, and if possible, a different antimicrobial class should be used.

\section{Selecting the Appropriate Antimicrobial Regimen}

Goal of Therapy. Inappropriate treatment can lead to failed bacterial eradication, the selection of resistant bacteria, complications due to the spread of these organisms, and a resulting infection that is more challenging to treat. The goal of appropriate antimicrobial treatment, therefore, is to maximally reduce or eradicate the bacterial load in order to achieve clinical success and minimize the potential for development of resistance. To minimize the risk of resistance development, current IDSA/ ATS guidelines suggest reducing the duration of therapy to a minimum of 5 days, though a longer duration may be required if the initial therapy was not active against the infection or if an extrapulmonary infection exists. ${ }^{9}$ 


\begin{tabular}{|c|c|c|c|c|c|}
\hline Agent & $\begin{array}{l}\mathrm{MIC} 90^{\mathrm{a}} \\
(\mathrm{mg} / \mathrm{L})\end{array}$ & $\begin{array}{c}\text { 24-h Serum } \\
\text { AUC } \\
(\mathrm{mg} / \mathrm{h} / \mathrm{L})\end{array}$ & $\begin{array}{l}\text { Fraction } \\
\text { Unbound }\end{array}$ & $\begin{array}{c}\text { 24-h Free } \\
\text { AUC } \\
(\mathrm{mg} / \mathrm{h} / \mathrm{L})\end{array}$ & $\begin{array}{l}\text { Free AUC/ } \\
\text { MIC } 90\end{array}$ \\
\hline $\begin{array}{l}\text { Moxifloxacin } \\
400 \mathrm{mg} \mathrm{q} 24 \mathrm{~h}\end{array}$ & 0.25 & 48 & 0.6 & 28.8 & 115 \\
\hline $\begin{array}{l}\text { Gemifloxacin } \\
320 \text { mg q24h }\end{array}$ & 0.03 & 9.93 & 0.35 & 3.48 & 116 \\
\hline $\begin{array}{l}\text { Levofloxacin } \\
750 \text { mg q24h }\end{array}$ & 1 & 90.7 & 0.7 & 63.5 & 64 \\
\hline $\begin{array}{l}\text { Levofloxacin } \\
500 \mathrm{mg} \mathrm{q} 24 \mathrm{~h}\end{array}$ & 1 & 48 & 0.7 & 33.6 & 34 \\
\hline
\end{tabular}

an vitro activity does not necessarily imply clinical effectiveness.

$A U C=$ area $u$ under the concentration-time curve; $M I C=$ minimum inhibitory concentration.

IDSA/ATS Guidelines for Empiric Treatment of CAP. The IDSA/ATS guidelines for the empiric treatment of patients with CAP take into account the site of care and the potential pathogens (Figure 4). ${ }^{9}$ For hospitalized patients in the general medical ward, monotherapy with a respiratory fluoroquinolone (levofloxacin, moxifloxacin, or gemifloxacin) or combination therapy with a $\beta$-lactam and macrolide is generally recommended.

For severe cases requiring ICU admission, antimicrobial selection will depend on the presence of risk factors for Pseudomonas infection. P. aeruginosa, a typical hospital-acquired pathogen, is sometimes associated with CAP. The risk factors for infection by $P$. aeruginosa include a Gram stain consistent with a gram-negative infection, the presence of structural lung disease (bronchiectasis), repeated exacerbations of severe chronic obstructive pulmonary disease, corticosteroid therapy, recent broad-spectrum antimicrobial use, and malnutrition. ${ }^{9}$

For patients with no risk of a Pseudomonas infection, combination therapy with a $\beta$-lactam and either a macrolide or a respiratory fluoroquinolone is recommended. For patients allergic to $\beta$-lactams, a respiratory fluoroquinolone and aztreonam are recommended. If methicillin-resistant S. aureus (MRSA) is suspected (such as the case if prior influenza-like illness, necrotizing severe pneumonia, or if a sputum Gram stain shows gram-positive cocci in clusters), vancomycin or linezolid should be added to the regimen.

Patients at risk of a Pseudomonas infection should be given combination therapy that includes an antipneumococcal/antipseudomonal $\beta$-lactam (e.g., piperacillin/tazobactam, cefepime, imipenem, meropenem) plus an antipseudomonal fluoroquinolone, or the above $\beta$-lactam plus an aminoglycoside and azithromycin or the above $\beta$-lactam plus an aminoglycoside and an antipneumococcal fluoroquinolone (for patients allergic to penicillin substitute aztreonam for the $\beta$-lactam). ${ }^{9}$

Optimizing Pharmacokinetic and Pharmacodymanic Parameters. In addition to choosing an appropriate antimicrobial agent, it is important to use a regimen that optimizes a drug's pharmacokinetic-pharmacodynamic parameters to ensure bacterial eradication. For concentration-dependent agents, such as the fluoroquinolones, clinical outcomes and prevention of resistance development correlate with the peak concentration to MIC ratio and the area under the concentration-time curve (AUC) to MIC ratio. ${ }^{33}$ Therefore, increased dosing of these agents by increasing the $\mathrm{C}_{\max }$ and AUC would maximize their ability to eradicate bacteria.

Optimizing pharmacokinetic-pharmacodynamic parameters is the rationale for the development of the $750 \mathrm{mg}$, 5-day levofloxacin regimen in contrast to the traditional $500 \mathrm{mg}, 10$-day course. Increasing the levofloxacin dose from $500 \mathrm{mg}$ to $750 \mathrm{mg}$ nearly doubles the AUC and increases the AUC/MIC ratio, thus increasing the probability of achieving pharmacokinetic-pharmacodynamic targets. ${ }^{34}$ A randomized, double-blind, clinical trial showed no significant differences between the 2 regimens even when stratified by disease severity. ${ }^{35}$ Moreover, the short-course regimen is associated with less total drug usage, which can potentially reduce the risk of emergence of resistance.

Of the respiratory fluoroquinolones, gemifloxacin and moxifloxacin have higher AUC/MIC ratios for S. pneumoniae than either levofloxacin regimens (Table 2). ${ }^{36-40}$ Does this difference translate into improved clinical outcomes?

A prospective, randomized, double-blind trial compared moxifloxacin (400 mg daily) and levofloxacin (500 mg daily) for 7-14 days for the treatment of hospitalized, elderly patients ( $\geq 65$ years) with $\mathrm{CAP}^{41}$ At the test-of-cure visit, there was no significant difference in the clinical cure rate between the moxifloxacin group (92.9\%) and the levofloxacin group (87.9\%, $P=0.2)$, even when patients were stratified by disease severity or age. However, at the on-treatment visit ( 3 to 5 days after the start of therapy), a significantly greater percentage of patients receiving moxifloxacin had achieved clinical recovery than those receiving levofloxacin ( $97.9 \%$ vs. $90.0 \%, P=0.01$ ). This study suggests that using a more potent agent may allow for more rapid resolution of CAP symptoms. It is important to note that this trial used a levofloxacin dose of $500 \mathrm{mg}$ and not the $750 \mathrm{mg}$ dose currently recommended by IDSA/ATS Guidelines. ${ }^{9}$

\section{Summary}

When managing patients with CAP, it is important to choose the most appropriate site of care as it impacts the extent of diagnostic testing, the empiric selection of antimicrobials, as well as the overall health care costs. Hospital and ICU admission should be reserved for the more severely ill patients who are at a greater risk of death. For all disease severities, S. pneumoniae is the most common cause. Resistance of this pathogen is prevalent and growing and local resistance profiles should be consulted before selecting empiric therapy. Rapid initiation of appropriate antimicrobial therapy is critical in achieving successful clinical outcomes. Newer dosing regimens are attempting to optimize the pharmacokineticpharmacodynamic parameters of agents to ensure successful and more rapid eradication of the bacterial pathogen.

\section{DISCLOSURES}

Thomas M. File, Jr., has received research funding from Cerexa, Ortho-McNeil, Pfizer, Protez, Rib-X, and Wyeth. He serves as a consultant to Advanced Life Sciences, Bayer, Cerexa, Cubist, GlaxoSmithKline, Ortho-McNeil, Merck, Nabriva, Oscient, Protez, sanofi-aventis, Schering-Plough, and Wyeth. He is also a member of the speakers' bureaus for Astellas, Theravance, Merck, Ortho-McNeil, Oscient, Pfizer, Schering-Plough, and Wyeth. 
Marco P. Cicero, PhD, of Vemco MedEd, LLC, contributed medical writing and editorial assistance. This article is being published as part of a supplement to the START continuing education program for pharmacists and physicians. It is supported by an educational grant from Schering-Plough Corporation.

\section{REFERENCES}

1. Kung H-C, Hoyert DL, Xu J, Murphy SL. Deaths: final data for 2005. Natl Vital Stat Rep. 2008;56(10):1-121.

2. Niederman MS, Mandell LA, Anzueto A, et al. Guidelines for the management of adults with community-acquired pneumonia: diagnosis, assessment of severity, antimicrobial therapy, and prevention. Am J Respir Crit Care Med. 2001;163(7):1730-54.

3. Colice GL, Morley MA, Asche C, et al. Treatment costs of communityacquired pneumonia in an employed population. Chest. 2004;125(6):2140-45. 4. Bartlett JG, Dowell SF, Mandell LA, File TM, Jr., Musher DM, Fine MJ. Guidelines from the Infectious Diseases Society of America: practice guidelines for the management of community-acquired pneumonia in adults. Clin Infect Dis. 2000;31(2):347-82.

5. File TM. Community-acquired pneumonia. Lancet. 2003;362(9400):19912001.

6. Gonzales R, Steiner JF, Sande MA. Antibiotic prescribing for adults with colds, upper respiratory tract infections, and bronchitis by ambulatory care physicians. JAMA. 1997;278(11):901-04.

7. File TM, Jr. Judicious use of antibiotics to treat respiratory tract infections. Curr Opin Infect Dis. 2002;15(2):149-50.

8. Ball P, Baquero F, Cars O, et al. Antibiotic therapy of community respiratory tract infections: strategies for optimal outcomes and minimized resistance emergence. J Antimicrob Chemother. 2002;49(1):31-40.

9. Mandell LA, Wunderink RG, Anzueto A, et al.; Infectious Diseases Society of America and American Thoracic Society. Infectious Diseases Society of America/American Thoracic Society consensus guidelines on the management of community-acquired pneumonia in adults. Clin Infect Dis. 2007;44(Suppl 2):S27-S72.

10. Fine MJ, Auble TE, Yealy DM, et al. A prediction rule to identify low-risk patients with community-acquired pneumonia. N Engl J Med. 1997;336(4):243-50

11. Lim WS, van der Eerden MM, Laing R, et al. Defining communityacquired pneumonia severity on presentation to hospital: an international derivation and validation study. Thorax. 2003;58(5):377-82.

12. Capelastegui A, Espana PP, Quintana JM, et al. Validation of a predictive rule for the management of community-acquired pneumonia. Eur Respir J. 2006;27(1):151-57. Available at: http://erj.ersjournals.com/cgi/ reprint/27/1/151. Accessed February 12, 2009.

13. Karchmer AW. Increased antibiotic resistance in respiratory tract pathogens: PROTEKT US—an update. Clin Infect Dis. 2004;39(Suppl 3):S142-S150

14. Doern GV, Brown SD. Antimicrobial susceptibility among communityacquired respiratory tract pathogens in the USA: data from PROTEKT US 2000-01. J Infect. 2004;48(1):56-65.

15. The Alexander Network. Available at: http://www.alexandernetwork. com. Accessed September 3, 2008.

16. Critchley IA, Brown SD, Traczewski MM, Tillotson GS, Janjic N. National and regional assessment of antimicrobial resistance among community-acquired respiratory tract pathogens identified in a 20052006 U.S. Faropenem surveillance study. Antimicrob Agents Chemother. 2007;51(12):4382-89.

17. Karlowsky JA, Thornsberry C, Jones ME, Evangelista AT, Critchley IA, Sahm DF. Factors associated with relative rates of antimicrobial resistance among Streptococcus pneumoniae in the United States: results from the TRUST Surveillance Program (1998-2002). Clin Infect Dis. 2003;36(8):963-70. 18. Clinical and Laboratory Standards Institute. Performance Standards for Antimicrobial Susceptibility Testing: Eighteenth Informational Supplement. Wayne, PA: Clinical and Laboratory Standards Institute; 2008. CLSI Document M100-S18.

19. File TM, Jr. Clinical implications and treatment of multiresistant Streptococcus pneumoniae pneumonia. Clin Microbiol Infect. 2006;12(Suppl 3):31-41.
20. Cabellos C, Ariza J, Barriero B, et al. Current usefulness of procaine penicillin in the treatment of pneumococcal pneumonia. Eur J Clin Microbiol Infect Dis. 1998;17(4):265-68.

21. Feikin DR, Schuchat A, Kolczak M, et al. Mortality from invasive pneumococcal pneumonia in the era of antibiotic resistance, 1995-1997. Am J Public Health. 2000;90(2):223-29.

22. Moroney JF, Fiore AE, Harrison LH, et al. Clinical outcomes of bacteremic pneumococcal pneumonia in the era of antibiotic resistance. Clin Infect Dis. 2001;33(6):797-805.

23. Yu VL, Chiou CC, Feldman C, et al. An international prospective study of pneumococcal bacteremia: correlation with in vitro resistance, antibiotics administered, and clinical outcome. Clin Infect Dis. 2003;37(2):230-37.

24. Daneman N, McGeer A, Green K, Low DE. Macrolide resistance in bacteremic pneumococcal disease: implications for patient management. Clin Infect Dis. 2006;43(4):432-38.

25. Lonks JR, Garau J, Gomez L, et al. Failure of macrolide antibiotic treatment in patients with bacteremia due to erythromycin-resistant Streptococcus pneumoniae. Clin Infect Dis. 2002;35(5):556-64.

26. Rzeszutek M, Wierzbowski A, Hoban DJ, Conly J, Bishai W, Zhanel GG. A review of clinical failures associated with macrolide-resistant Streptococcus pneumoniae. Int J Antimicrob Agents. 2004;24(2):95-104.

27. Van Kerkhoven D, Peetermans WE, Verbist L, Verhaegen J. Breakthrough pneumococcal bacteremia in patients treated with clarithromycin or oral $\beta$-lactams. J Antimicrob Chemother. 2003;51(3):691-96.

28. Anderson KB, Tan JS, File TM, Jr, et al. Emergence of levofloxacinresistant pneumococci in immunocompromised adults after therapy for community-acquired pneumonia. Clin Infect Dis. 2003;37(3):376-81.

29. Davidson R, Cavalcanti R, Brunton JL, et al. Resistance to levofloxacin and failure of treatment of pneumococcal pneumonia. N Engl J Med. 2002;346(10):747-50

30. Clavo-Sanchez AJ, Giron-Gonzalez JA, Lopez-Prieto D, et al. Multivariate analysis of risk factors for infection due to penicillin-resistant and multidrug-resistant Streptococcus pneumoniae: a multicenter study. Clin Infect Dis. 1997;24(6): 1052-59.

31. Vanderkooi OG, Low DE, Green K, Powis JE, McGeer A. Predicting antimicrobial resistance in invasive pneumococcal infections. Clin Infect Dis. 2005;40(9):1288-97.

32. Harwell JI, Brown RB. The drug-resistant pneumococcus: clinical relevance, therapy, and prevention. Chest. 2000;117(2):530-41.

33. Gunderson BW, Ross GH, Ibrahim KH, Rotschafer JC. What do we really know about antibiotic pharmacodynamics? Pharmacotherapy. 2001;21(11 Pt 2):S302-S318.

34. Gotfried MH, Danziger LH, Rodvold KA. Steady-state plasma and intrapulmonary concentrations of levofloxacin and ciprofloxacin in healthy adult subjects. Chest. 2001;119(4):1114-22.

35. Dunbar LM, Wunderink RG, Habib MP, et al. High-dose, short-course levofloxacin for community-acquired pneumonia: a new treatment paradigm. Clin Infect Dis. 2003;37(6):752-60.

36. Jones RN, Biedenbach DJ. Comparative activity of garenoxacin (BMS 284756), a novel desfluoroquinolone, tested against 8,331 isolates from community-acquired respiratory tract infections: North American results from the SENTRY Antimicrobial Surveillance Program (1999-2001). Diagn Microbiol Infect Dis. 2003;45(4):273-78.

37. Scheld WM. Maintaining fluoroquinolone class efficacy: review of influencing factors. Emerg Infect Dis. 2003;9(1):1-9.

38. Levaquin [prescribing information]. Raritan, NJ: Ortho-McNeil-Janssen Pharmaceuticals, Inc.; January 2007.

39. Avelox [prescribing information]. Kenilworth, NJ: Schering-Plough; June 2002.

40. Factive [prescribing information]. Waltham, MA: Oscient Pharmaceuticals; February 2004.

41. Anzueto A, Niederman MS, Pearle J, Restrepo MI, Heyder A, Choudhri SH. Community-Acquired Pneumonia Recovery in the Elderly (CAPRIE): efficacy and safety of moxifloxacin therapy versus that of levofloxacin therapy. Clin Infect Dis. 2006;42(1):73-81. 